\title{
From the jungle to urban centers: body image and self-esteem of women in three different cultures
}

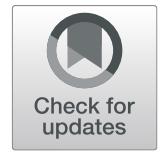

\author{
Julia Odinga $\cdot$ Erich Kasten $\mathbb{D}$
}

Received: 20 January 2019 /Accepted: 29 April 2020 / Published online: 20 May 2020

(C) The Author(s). 2020 Open Access This article is licensed under a Creative Commons Attribution 4.0 International License, which permits use, sharing, adaptation, distribution and reproduction in any medium or format, as long as you give appropriate credit to the original author(s) and the source, provide a link to the Creative Commons licence, and indicate if changes were made. The images or other third party material in this article are included in the article's Creative Commons licence, unless indicated otherwise in a credit line to the material. If material is not included in the article's Creative Commons licence and your intended use is not permitted by statutory regulation or exceeds the permitted use, you will need to obtain permission directly from the copyright holder. To view a copy of this licence, visit http://creativecommons.org/licenses/by/4.0/.

Summary The aim of this study is to compare body image, body perception, body satisfaction, body-related self-esteem and overall self-esteem of women from three different cultural backgrounds. The survey covers a sample of 187 women, including 133 Germans, 31 Q'eqchi', and 23 Colombians. Two groups (in Germany and Colombia) live in urban centers, while one group (in Guatemala: Q'eqchi') is a jungle-based ethnic group descended from the Maya where the body perception was largely unaffected by media. The instruments used in this study are the Figure Rating Scale, the Body-Esteem Scale and the Rosenberg Self-Esteem Scale. According to the study, German and Colombian women prefer a significantly slimmer body and perceive themselves more critically than Q'eqchi'. There are no significant differences in body perception between German and Colombian women. Q'eqchi' women do not have significantly higher body satisfaction than German and Colombian women. Although German women have significantly higher body satisfaction than Colombian women, Q'eqchi' women have the highest body-related self-esteem on average. Colombian women in turn have a higher body-related self-esteem than German women. There is a positive correlation between body satisfaction with both body-related self-esteem and overall self-esteem in all three groups. In conclusion, the German and Columbian women living in urban settings look much slimmer, prefer much slimmer bodies and have lower body-related self-esteem, compared to jungle-dwelling Q'eqchi'

J. Odinga $\cdot$ E. Kasten $(\bowtie)$

Medical School Hamburg, Am Kaiserkai 1, 23564 Hamburg, Germany

e-mail: EriKasten@aol.com

E. Kastenhttp://www.erich-kasten.de 
women in Guatemala.

Keywords Body image $\cdot$ Body perception - Body satisfaction · Body-related selfesteem · Self-esteem · Guatemala · Columbia · Germany

\section{Introduction}

In 2003, the United Nations Educational, Scientific and Cultural Organization (UNESCO) passed The Convention for the Safeguarding of Intangible Cultural Heritage (available from ich.unesco.org/en/convention), which intends to strengthen the information exchange and cooperation among governments, social organizations and ordinary people in order to protect and utilize intangible cultural heritage (Zhang 2019a, 2019b). The Q'eqchi' are a small group of people who live in the deep jungle of Guatemala and whose customs and behavior have hardly been investigated so far. There is no electricity in their villages and therefore modern technologies have not yet moved in. It is impelling to compare the untouched attitudes about the appearance of the human body of the women living there with those of a large city in Central America, as well as with those of a technologically advanced country in Europe. There are several anthropological studies comparing tribal ethnographic groups with small populations on the one hand and Western countries on the other hand (Zhou et al. 2019). Examples include clans, tribes, tribal alliances, ancient empires, feudal kingdoms and feudal empires, as well as nations and nation-states that emerged in modern times (Liu and Zhang 2018). Nowadays, cultural differences have become increasingly respected, and people realized that every nation has the right and obligation to develop its own culture (Zhang 2019a, 2019b). Between developing and developed countries, there are still disparities in education completion, health, the labor market, the incidence of poverty, and in living standards. The central question this paper seeks to answer is whether there are differences in basic attitudes to the beauty of the human body among different cultures.

Social norms not only vary within cultures, social strata, ethnicity and gender, but also vary over time leading to substantial changes in body shape preferences and the epidemiology of eating disorders (Stern 2018).

The perception of one's own body is an increasingly important factor for many people. However, the cognitive representation of one's own body does not always correspond to the ideal body image (Slade 1994), which is conditioned by different genetic, social and cultural influences. The essential question of this study is to what extend body-ideal, body-satisfaction and self-esteem are related. For this purpose, 187 women from three countries were interviewed: Germany, Guatemala and Colombia. While the German and Colombian women interviewed live in big cities, the Q'eqchi' women from Guatemala belong to an ethnic group descended from the Maya and live in a tropical rainforest.

Most of recent studies only compared different ethnic groups living together in the same country. For example, Yu and Perez (2019) compared white, Latinx, and Asian American undergraduates. Among all three groups, body dissatisfaction, 
maternal criticism, and gender were significantly associated with disordered eating. Body dissatisfaction did not differ significantly between female and male undergraduates in any of the three ethnic groups. Among Asian Americans, perceived maternal criticism was strongly associated with disordered eating. This study highlights the potential role of culture in eating disorders, particularly in self-construal orientations. Javier and Belgrave (2019) have discovered that the most essential reason for which women of Asian origin living in the U.S. try to be leaner and more attractive than white-skinned is that they are not white.

El Ansari and Berg-Beckhoff (2019) assessed nationality- and sex-specific associations between health status, healthy behavior, weight satisfaction, and body image concern via a cross-sectional survey of 5888 undergraduates in Egypt, Palestine, and Finland. High BMI and more depressive symptoms were positively associated with body image concern irrespective of nationality or gender. With a random sample of 4934 adults from slums of Nairobi, Ettarh et al. (2013) analyzed perceptions of current and ideal body image by using 18 silhouette drawings of body sizes ranging from very thin to very obese. As claimed by this investigation, $43.4 \%$ of women and $17.3 \%$ of men were overweight. More than half $(53 \%)$ of those who were overweight underestimated their weight; but more than one-third of these men and women preferred body sizes classified as overweight or obese. This study highlights the strong preference for larger body size among adults in the slums of Nairobi. On the other hand, Terhoeven et al. (2019) examined the prevalence of eating disorders and its predictors among adolescent females in Burkina Faso (West Africa). As stated in that study, $16 \%$ of respondents had a BMI below WHO age-standardized 5th percentile, while only $4 \%$ were above the 85 th percentile; but most respondents wanted to be larger. Conversely, a desired thinner body was associated with greater media exposure. The findings of these authors suggest that increasing media exposure in resource-limited settings may lead to increased body dissatisfaction.

In Colombia, there are only a few works written on this topic; in Guatemala, no works have beenfound. In particular, indigenous peoples in Guatemala and their relationships with their bodies have so far received no scientific investigation. Thus, the results presented here can be regarded as an important contribution to this field of research.

Obesity is negatively regarded in big cities of the industrial nations and weight loss diets are culturally promoted. However, during a three-month stay with the Q'eqchi' in Guatemala, the first author of this article observed that a physiologically healthy status leads to greater recognition within their social group. In addition, a liberal approach with nudity and with their own body was observed: Q'eqchi' women were not distressed about being overweight or having a too corpulent body. It was noted that these women had access to neither scales nor mirrors, which may be a contributing factor. Furthermore, Q'eqchi' women barely had access to social media because there was no electricity. The body ideal was likely largely unaffected by television or the Internet.

"A Colombian woman is never ugly; she has only one poor husband." This typical quote represents the image of women and a possible standard of measurement for beauty in the city of Cali, Columbia. Despite the fact that both Colombia and 
Guatemala are Latin American countries, the social background and social role of the women interviewed in this study differed greatly between the two countries.

Before 1989, Buhrich observed that obesity was seen as a sign of wealth, abundance, strength, and fertility in developing countries (Buhrich 1981), however, in 2004, a comprehensive review showed that between 1989 and 2003, this view has shifted. Obesity in the developing world can no longer be considered solely as a disease of groups of higher socio-economic status (Monteiro et al. 2004). In the 1970s, overweight individuals in the western industralized nations were related with negative personal characteristics (Berscheid et al. 1973). A systematic review published in 2012 confirms that the stigma of the obese has intensified; Puhl and Brownell expanded upon their first systematic review in 2001 and showed that weight discrimination remains persistent in settings of employment, health care, and education. Expanding beyond these domains, recent studies also demonstrate the presence of weight bias in the media and in close interpersonal relationships with family members and romantic partners, and indicate that bias and stigma pose threats to emotional and physical health of obese individuals (Puhl and Brownell, 2012). In addition, dissatisfaction with the body is increasing exponentially within western societies (Polivy and Herman 2002). As a result, the answer of whether or not German and Colombian women have body ideals slimmer than the ideals revered by Q'eqchi' women can be derived.

This work also deals with self-esteem, since one's own physical experience is a major component of how one perceives and evaluates oneself. Positive correlations between body experience and self-esteem have been found particularly in children and adolescents (Thornton and Ryckman 1991; Lerner et al. 1991; Astleitner and Holzner 2006).

Unfortunately, the terms body image, body satisfaction, body-related selfesteem and self-esteem are not uniformly defined. Body image is the mental representation of body shape, profile and size (Slade 1994); here, subjective perceptions, cognitive attitudes, thoughts, fantasies, emotions and socio-demographic variables are playing a role (Salter 1999). Body image is defined by how people experience their own embodiment, especially, but not exclusively, their physical appearance (Cash 2012). The subjective body image is thus different from the objectively measurable body (Schemer 2003; Röhricht et al. 2004). With "body perception", all dimensions are described, which are based on primary process events, i.e. the result of a complex interaction between interoception, exteroception, and preexisting body templates (Costantini 2014). Body satisfaction is the satisfaction with the appearance of the body (Blake 2015), it is a subjective evaluation. Self-esteem is the result of an affective component from one's own evaluations of personality traits, abilities, or emotional experiences (Lohaus and Vierhaus 2013). People with high self-esteem have a safer, more positive belief of themselves (Campbell 1990). Body-esteem describes the extent of positive or negative attitudes of a person towards his or her body (Mendelson et al. 2001), which can be divided into physical attractiveness, body strength, physical condition, and weight concern (Franzoi and Shields 1984; Tucker 1981). The personal opinion of the self often differs from the opinion others hold (Confalonieri et al. 2008).

Body ideals change not only in different cultures, but also with the passage of time. Over the years, most societies in the world considered a well-formed, 
voluptuous female body attractive. However, since about the end of the 1960s, Western cultures started to prefer a thin female figure (Anderson et al. 1992). Using research from 54 cultures, Anderson and her colleagues found a negative correlation between the exuberance of the body ideal and the appreciation of the woman's workforce; in societies where the woman's labor power is primarily valued, leaner body ideals prevail. Since women in certain cultures are primarily assigned to the role of a mother, a full-figured body could increase the likelihood of a successful pregnancy and lactation. Slimmer body ideals exist in countries that condemn pregnancy during adolescence (Frisch 1990, cited from Anderson et al. 1992). Findings of a meta-analysis performed by Grabe et al. (2008) suggest that exposure to mass media depicting the thin ideal body may be linked to body image disturbance in women.

In the long history of mankind, people tend to choose water-rich areas with a warm and humid climate. Most of the equatorial areas are warm while the northern countries are cold (Gao et al. 2017). The "Temperature" hypothesis - according to which more body fat is necessary in colder countries, so as not to freeze - could not be confirmed; in fact, it was the other way around. The "Food Security" hypothesis suggests that a leaner body ideal is preferred in countries with a secure food supply; while a lush body ideal is preferred in countries with an insecure food supply. While obesity used to be seen as a sign of wealth, abundance, strength, and fertility in developing countries (Buhrich 1981), overweight persons in industrial nations are still associated with negative characteristics as e.g. weakness of will or sluggishness (Berscheid et al. 1973, Puhl \& Brownell, 2012). Slimness in poorer countries is more likely to signal poverty and disease (Schemer 2003), while slimness is equated with beauty in high-tech western societies (Berscheid et al. 1973, Puhl \& Brownell, 2012). Here, slimness is associated with fitness and self-control - an aspect that can serve as an advantage in a society geared to individualism and competition (Thompson et al. 1999, quoted by Schemer 2003).

Ultimately, there are several factors that can be assumed to have a strong impact on the body ideal of women in different cultures: (1) Since millennia, having many children was once guarantee of survival in old age for both parents; because that ensured survival when a parent had become frail. This ideal still applies today in developing countries where there is insufficient food supply; voluminous women are considered more fertile and therefore more attractive than thin women. (2) In the technologically advanced states, old-age survival is covered with pension insurance and no longer has to be guaranteed by having many children to ensure care. The ideal female body has shifted from voluminous to virgin and slim-looking women. Thanks to slenderness, hair coloring, make-up, cosmetic surgery and body hair removal, even adult women today appear young and untouched. (3) The media plays a significant role in communicating the ideal of a slim and adolescentlooking body; ranging from cinema films to internet pornography, ideals of the body's appearance are widely conveyed in industrialized countries while the inhabitants in developing countries have hardly or, as with the Q'eqchi', no access.

Not all of these factors can be examined in the present study. Therefore the following hypotheses have been selected for further investigation: 
H 1: German women prefer a significantly slimmer body than Guatemalan Q'eqchi' women.

H 2: German women prefer a significantly slimmer body than Colombian women.

H 3: Colombian women prefer a significantly slimmer body than Guatemalan Q'eqchi' women.

H 4: Compared to Guatemalan Q'eqchi' women, German women have a significantly more critical self-perception.

H 5: Compared to Colombian women, German women have a significantly more critical self-perception.

H 6: Compared to Guatemalan Q'eqchi' women, Columbian women have a significantly more critical self-perception.

H 7: Guatemalan Q'eqchi' women show a significantly higher level of body satisfaction than German women.

$\mathrm{H}$ 8: Colombian women show a significantly higher level of body satisfaction than German women.

H 9: Guatemalan Q'eqchi' women show a significantly higher level of body satisfaction than Colombian women.

H 10: Guatemalan Q'eqchi' women show a significantly higher level of bodyrelated self-esteem than German women.

H 11: Colombian women have a significantly higher level of body-related selfesteem than German women.

H 12: Guatemalan Q'eqchi' women show a significantly higher level of bodyrelated self-esteem than Colombian women.

H 13: Guatemalan Q'eqchi' women show a significantly higher level of selfesteem than German women.

H 14: Colombian women have a significantly higher level of self-esteem than German women.

H 15: Guatemalan Q'eqchi' women show a significantly higher level of selfesteem than Colombian women.

$\mathrm{H}$ 16: There is a positive correlation between body satisfaction and body-related self-esteem: the higher the body-related self-esteem of a person, the higher the body satisfaction.

$\mathrm{H}$ 17: There is a positive correlation between body satisfaction and self-esteem: the more satisfied a person is with their body, the higher their self-esteem.

$\mathrm{H}$ 18: There is a positive correlation between body-related self-esteem and selfesteem: the higher the body-related self-esteem of a person, the higher the selfesteem.

\section{Samples}

The indigenous population in Guatemala accounts for about $49 \%$ of the total population. The Q'eqchi' people mentioned in this study are descendants of the Maya, living in the tropical jungle where there is an annual average temperature of about 27.9 degrees Celsius (Climate-data.org, n.d.-a, b). About $93 \%$ of Mayan women 
work exclusively in the home (Klitzke Rozas 2015); they get married around the age of 15 and from then on, are responsible for preparing food and bringing up children. Women typically only leave their residential areas in order to gather the corn or beans around their home. Pregnancy during adolescence is the rule; women who have no children by their mid-twenties are socially outcast and are likely to be married with male social outcasts of the village, since their main function is to reproduce. Childless women, who cannot conceive due to fertility issues, suffer severe reputation impairment and endure a high risk of being abandoned by their husbands.

Despite fertile soil, 50-80\% of indigenous children outside the city are affected by chronic malnutrition (Kruchem 2016), which can lead to a decline in physical and mental development (Wagner, 2013). Seventy percent of indigenous Mayans in Guatemala live in poverty (Klitzke Rozas 2015). Large commercial farms account for almost two thirds of the total agricultural land in Guatemala. The tropical fruits and vegetables cultivated there are mainly sold to cities and there is little access to animal products (Kruchem, 2015). As a result, many indigenous families have insufficient land to be able to produce enough food to feed themselves (Kruchem, 2015). Their nutrition comes almost entirely from corn and beans - this unilateral diet increases susceptibility to infectious diseases (Kruchem 2016). In addition, there is a high level of bacterially contaminated water (UNICEF 2010).

In Nueva Mercedes, the village where the Q'eqchi' involved in this study live, there is not a secure food supply. The overall nutrition has deteriorated in the past 50 years, since the area is owned by international landlords, who grow palm oil around the village. Due to insufficient land, fruits and vegetables can only be bought at markets which are about an hour away from their village and it costs money to travel there. Corn and beans are the basic food sources and the little space for growing them is shared within the community. Due to pesticides used by the international farmers, most of the water is contaminated and many rivers are dried out by the palm oil production.

Based on the findings of Anderson et al. (1992), it is suggested that the Q'eqchi' Maya are more likely to have a lush body ideal.

The way of life of Colombian women living in the city of Cali, where the Colombian participants in this study reside, is entirely different. In 2013, the rate of unemployment among women in Colombia was $11.3 \%$ (Dane, 2013). Instead of adopting the traditional role of the wife and mother in adolescence, young women in Columbia can be trained to participate in the work force (Federal Ministry for Economic Cooperation and Development 2014). In 2015, the number of teenage pregnancies was $17 \%$ (Suárez Calle 2015). The average annual temperature in Cali is 24 degrees Celsius (Climate-data.org, n.d.-a, b). In terms of food security, Colombia has enjoyed a positive development in recent years. While $40 \%$ of the Colombian population was considered poor in 2010, in 2014 it was only $28.5 \%$ (Walter 2015). In 2015, 91.4\% of the population had an adequate connection to a drinking water supply (Federal Ministry for Economic Cooperation and Development 2017). On the other hand, most of the inhabitants of rural regions suffer from an insecure food situation (see: Action Against Hunger 2015). Colombia is a middle-income Latin American country compared to Guatemala, which is classified 
as a low-income country (Federal Ministry for Economic Cooperation and Development 2014). Due to the adoption of Western ideals, a slim body ideal is likely among the women living in the city of Cali; Cali is considered the "city of eternally beautiful women" (Castillo 2008). Here, plastic surgery is a common desire (Castillo 2008); the most popular surgeries desired are breast augmentation, liposuction and buttock augmentation (Depiel 2016). It is not uncommon for parents to give their daughter the permission and financial backing for a cosmetic procedure as a present for her 15th birthday - a magical date in Latin American culture celebrating puberty (Käufer 2013). Especially for young girls living in the lower social strata, cosmetic surgery is a ticket to upper-class society (Käufer 2013). People still want to look like Europeans because of the conquistadors (Twigg 2017), while the Afro-Colombian ideal of beauty has also prevailed, which represents a body with particularly prominent female curves (Käufer 2013). In Colombia, television is very popular and almost exclusively shows beautiful people (Twigg 2017). In Colombia, Venezuela and Brazil in particular, it is believed that the only way to be a valued member of society is to look beautiful (Twigg 2017).

According to statistics from the International Society of Aesthetic Plastic Surgery (ISAPS), in 2018 there were 408,789 cosmetic procedures in Colombia. This puts Colombia in eighth place worldwide for the highest number of cosmetic procedures (ISAPS: International Society of Aesthetic Plastic Surgery 2018). In Colombia, 12 plastic surgeries per thousand people take place - a remarkably high number considering their large population and that millions of people live below the poverty line (Twigg 2017).

Germany is one of the high-tech countries with a good social system. Nobody has to starve in Germany - on the contrary, more and more emphasis is placed on healthy nutrition. The drinking water is constantly monitored for safety and hygiene. The average annual temperature is between $12^{\circ}$ and $14^{\circ}$ Celsius. With only $2.4 \%$, Germany has one of the lowest rates of youth pregnancies worldwide (Profamilia 2009). The average age for the first pregnancy has been rising for years; in 2016, the average age was recorded at 30.4 years old (Destatis 2016a), and in 2018 it was 31.3 years. Most German women aspire to a high level of education. In $2016,74.5 \%$ of German women were employed, including many mothers (Destatis 2016 b). Germany is also one of the countries with the highest rates of plastic surgery, occupying fourth place, with 922,056 cosmetic procedures occurring in 2018 (ISAPS: International Society of Aesthetic Plastic Surgery 2018).

A total of 235 women completed the questionnaire. Forty-eight of these questionnaires were not included in the final evaluation due to missing information. Thus, the total sample consisted of 187 persons. The German and Colombian sample groups were surveyed using an online questionnaire. Due to a lack of electricity and a local illiteracy rate of more than 70\% (UNESCO 2006), the Q'eqchi' subjects were visited personally at home and interviewed using the paper-pencil method on site. Participation was voluntary for all subjects. The group of Q'eqchi' women consisted of 31 subjects, the group of Colombian women consisted of 23 subjects, and the group of German women consisted of 133 subjects. How the education and employment distributions of the three groups are composed is illustrated in Table 1 . 


\section{Methods}

To record body experience, the Figure Rating-Scale (Stunkard et al. 1983) was used. This scale consists of drawings that differ in body weight (Blake 2015). In this study, female figures were presented in nine weight grades from very slim (1) to obese (9). To measure body satisfaction, the subjects should show which figure a] best corresponds to their own body shape (actual state) and b] which of the figures most closely resembles their desired body shape (target state, see: Blake 2015). The body satisfaction, then results from the amount of the discrepancy between the actual body shape vs. the desired body shape. Positive values indicate that the individual ranks herself as more overweight than desired and negative values indicate that the individual ranks herself thinner than desired. If the indication of her own body image is identical with that of the desired body image, one can assume the subject is satisfied with her own body (Kreikebaum 1999). The validity and retest reliability of the Figure Rating Scale are considered to be high (Fisseni, 1997). Cronbach's Alpha for the questions regarding the Figure Rating Scale was 0.61 .

In addition, the body mass index (BMI) was recorded, which is a measure of the weight of a person's body in relation to height (Quetelet 1832). An index above 25 is considered by the World Health Organization to be overweight, with a score below 18.5 being underweight (World Health Organization 2016). Which figure of the Figure Rating Scale is assigned to which BMI can be taken from Table 2.

Body-related self-esteem was measured using the Body-Esteem Scale by Franzoi and Shields (1984). Through this, the subjective feeling about specific body parts and functions can be expressed on a five-point Likert scale ( 1 = I have strong negative feelings to $5=\mathrm{I}$ have strong positive feelings). Thirty two body parts and functions are listed, each of which can be assigned to the gender dimensions Physical Condition, Weight Concern or Sexual Attractiveness and are tailored directly to women. The test has satisfactory internal consistency and high convergent validity (Franzoi and Shields 1984, Rosenberg, 1986). Cronbach's Alphas for these items was 0.91 .

To assess self-esteem, the Rosenberg Self-Esteem Scale by Rosenberg (1986) was used. It consists of ten items and is answered via a five-point Likert scale $(1=$ does not apply at all to $5=$ completely true). Then the individually specified values are added up to a sum score. The scale has a high reliability (Rosenberg 1986, Blascovich \& Tomaka, 1993). In this study, as in Pullmann and Allik (2000), a

Table 1 Description of the three samples (Mean values \pm SD)

\begin{tabular}{llll}
\hline & Guatemala (Q'eqchi') & Colombia (Cali) & Germany (Hamburg) \\
\hline Age (years) & $25.3 \pm 6.5$ & $23.3 \pm 5.1$ & $24.2 \pm 4.2$ \\
Years of education & $5.9 \pm 4.1$ & $15.6 \pm 3.3$ & $15.8 \pm 3.4$ \\
Weight $(\mathrm{kg})$ & $59.3 \pm 11.1$ & $65.0 \pm 15.4$ & $63.5 \pm 8.5$ \\
Height $(\mathrm{cm})$ & $151.4 \pm 7.7$ & $163.8 \pm 6.4$ & $169.4 \pm 6.2$ \\
BMI & $25.9 \pm 4.4$ & $24.2 \pm 5.4$ & $22.222 .2 \pm 3.2$ \\
\hline
\end{tabular}


Table 2 Figure Rating Scale: Figure and BMI (Stunkard et al. 1983)

\begin{tabular}{lllll}
\hline Figure & 1,2 & 3,4 & $5,6,7$ & 8,9 \\
\hline BMI & $15-18.9$ & $19-24.9$ & $25-29.9$ & $30-39.9$ \\
Interpretation & underweight & normal weight & overweight & obese \\
\hline
\end{tabular}

five-point Likert scale was used to give the subjects a wider range of responses. Cronbach's Alpha for the questions regarding the self-esteem scale was 0.82 for the positive and 0.85 for the negative items.

In addition, participants were asked, "Have you ever thought of surgically altering something on your body to beautify it?" In addition, access to various media was recorded using a five-point Likert scale ( $1=$ very often to $5=$ never). The question was "Which of the following media do you get information from and to what extent?" Cronbach's Alpha for the questions regarding the use of media was 0.66.

All questionnaires were translated into German, Spanish and Q'eqchi'. The questionnaire in Q'eqchi' was also adapted to accommodate for the Mayan numeral system.

\section{Results}

Since these are ordinarily scaled features and the samples are not very large, nonparametric tests were used (Mann-Whitney U-Test, Spearman's correlation). In addition, Bonferroni correction was performed on all hypotheses. The effect sizes were calculated according to Cohen (1992).

Access to different media was measured using a five-point Likert scale between $1=$ very often, and $5=$ never (a low value corresponds to high media usage). The mean value use of media among German women was $2.82(\mathrm{SD}=0.54, \mathrm{Md}=2.86)$, among Q'eqchi' women $3.65(\mathrm{SD}=0.70, \mathrm{Md}=3.71)$ and among Colombian participants $2.21(\mathrm{SD}=0.47, \mathrm{Md}=2.14)$.

A one-way ANOVA for the BMI (see Table 1) of all three nationalities was significant $(\mathrm{F}=11.236, p=0.000)$.

The mean value of the sum score of the self-esteem scale (Rosenberg 1986) was 37.45 in German subjects $(\mathrm{SD}=6.21, \mathrm{Md}=38.50)$. Q'eqchi' female received a score of $32.59(\mathrm{SD}=3.46, \mathrm{Md}=33.00)$ and the average of the Colombian women was $35.73(\mathrm{SD}=6.20, \mathrm{Md}=36.00)$. Higher values indicate a higher level of selfesteem $(1=$ Strongly disagree to $5=$ Strongly and completely agree $)$.

The first group of hypotheses examined the extent to which the three groups of women differ in terms of their body ideal. The mean value of the Q'eqchi' participants was just below the fourth figure of the nine-step Figure-Rating-Scale, i.e. a body in the upper "normal weight". The Colombians were between the second and third figures; this corresponds to a lower to normal weight body. The German participants were just below the Colombian women (see Table 3). For the hypothesis H1 the U-test by Mann \& Whitney confirmed a significant result regarding the difference between Q'eqchi' and German women $(\mathrm{z}=-4.630, p=0.001)$. Accordingly, German 
women prefer a significantly slimmer body than Q'eqchi'. The effect size according to Cohen (1992) is $d=0.73$ and corresponds to a mean effect. Even after the Bonferroni correction (for 9 hypotheses on this topic with a significance limit of $p<$ $0.0055)$, the difference remains significant. In contrast, for hypothesis $\mathrm{H} 2$, a difference between German and Colombian women could not be found $(\mathrm{z}=-0.610, p=$ 0.271). For the hypothesis H3, Colombian women also preferred a significantly slimmer body than Q'eqchi' women $(\mathrm{z}=-3.032, \mathrm{p}=0.001)$. The effect size according to Cohen (1992) is $d=0.88$ and corresponds to a strong effect. After the Bonferroni correction the difference remains significant. A one-way ANOVA for this first set of hypotheses for all three nationalities was not significant (in-group 1.01, between-group $1.72, \mathrm{~F}=1.698, p=0.17$ ).

The second group of hypotheses dealt with the perception of one's own body. The mean values of self-perception in the German and Guatemalan sample were just below the 4th figure of the Figure Rating Scale, in the Colombian sample at 4.35 significantly above (see Table 3 ).

In the comparison of the means of German and Q'eqchi' women, no significant difference $(z=-0.209, p=0.417)$ was found for hypothesis H4. However, under the premise that the BMI of German women is significantly lower than that of Q'eqchi' women $(\mathrm{z}=-4.765, p=0.001)$, German women assess themselves as significantly more fat and thus view their bodies more critically than the Q'eqchi' women. The effect size according to Cohen (1992) is $d=0.80$ and corresponds to a strong effect. Even after the Bonferroni correction, the difference remains significant.

For hypothesis H5, German and Colombian women do not differ significantly in their self-perception $(\mathrm{z}=-1.279, p=0.100)$. They both consider themselves similarly slim. However, the BMI of German women is significantly lower than that of Colombian women $(\mathrm{z}=-1.701, p=0.044)$. This can be interpreted as German women perceiving their bodies more critically than Colombian women do. However, the effect size according to Cohen (1992) is only $\mathrm{d}=0.28$ and corresponds to a weak effect. After the Bonferroni correction there is no significant difference.

For hypothesis H6, the comparison between Colombian and Q'eqchi' women is also non-significant $(\mathrm{z}=-1.043, p=0.148)$. However, a considerable difference was found due to the significantly lower BMI of the Colombian women $(\mathrm{z}=-$ 1.889, $p=0.029$ ). The effect size according to Cohen (1992) is $d=0.53$ and

Table 3 Results of the survey on body ideal, body perception and body satisfaction using the Figure Rating-Scale (Mean values \pm SD)

\begin{tabular}{|c|c|c|c|}
\hline & $\begin{array}{l}\text { Guatemala } \\
\left(Q^{\prime} \text { eqchi`) }\right.\end{array}$ & $\begin{array}{l}\text { Colombia } \\
\text { (Cali) }\end{array}$ & $\begin{array}{l}\text { Germany } \\
\text { (Hamburg) }\end{array}$ \\
\hline Body ideal $(\min .1$ to $\max .9$, mean $=5)$ & $3.97 \pm 1.83$ & $2.57 \pm 0.90$ & $2.47 \pm 0.73$ \\
\hline Body perception $(\min .1$ to $\max .9$, mean $=5)$ & $3.94 \pm 1.41$ & $4.35 \pm 1.41$ & $3.99 \pm 1.13$ \\
\hline $\begin{array}{l}\text { Body satisfaction (Diff. body ideal - body } \\
\text { perception) }\end{array}$ & $1.45 \pm 1.57$ & $1.22 \pm 0.67$ & $0.96 \pm 0.92$ \\
\hline $\begin{array}{l}\text { Body-related self esteem ( } \min .1 \text { to } \max .5 \text {, } \\
\text { mean }=3 \text { ) }\end{array}$ & $3.96 \pm 0.95$ & $3.55 \pm 0.47$ & $3.31 \pm 0.53$ \\
\hline Self esteem $(\min 10, \max 50$, mean $=30)$ & $32.59 \pm 3.46$ & $35.73 \pm 6.20$ & $37.45 \pm 6.21$ \\
\hline
\end{tabular}


corresponds to a medium effect. However, there is no significant difference after the Bonferroni correction. A one-way ANOVA for this second set of hypotheses for all three nationalities was not significant (in-group 1.49, between-group 1.59, $\mathrm{F}=1.07, p=0.36$ ).

The following set of hypotheses dealt with body satisfaction (see Table 3 ). The body satisfaction construct uses two different mean values: the averaged mean values represent how much slimmer the sample groups want to be and only positive values are included. The absolute mean values represent the desire to be both overweight and thinner, and include both positive and negative values. The averaged mean values of the German participants were $0.88(\mathrm{SD}=0.99, \mathrm{Md}=1.00)$, the Q'eqchi' participants $0.55(\mathrm{SD}=2.08, \mathrm{Md}=1.00)$ and those of the Colombian participants were 0.96 $(\mathrm{SD}=1.02, \mathrm{Md}=1.00)$. Lower mean values represent a lower real-ideal discrepancy and thus a higher body satisfaction, but not all values are included.

The absolute mean value of the German participants was $0.96(\mathrm{SD}=0.92, \mathrm{Md}=$ $1.00)$, of the Q'eqchi' participants $1.45(\mathrm{SD}=1.57, \mathrm{Md}=1.00)$ and of the Colombian participants $1.22(\mathrm{SD}=0.67, \mathrm{Md}=1.00)$. Since the absolute mean values include all data, they were used for the Mann-Whitney U-test.

For hypothesis H7, the comparison of the mean values of the German and Q'eqchi' women with respect to body satisfaction showed no significant deviation $(\mathrm{z}=-$ 1.587, $p=0.056$ ). When comparing German and Colombian women for hypothesis $\mathrm{H} 8$, a significant deviation was recorded $(\mathrm{z}=-1.912, p=0.028)$. The effect size according to Cohen (1992) is $\mathrm{d}=0.28$ and corresponds to a small effect. However, there is no significant difference after the Bonferroni correction with a significance limit of $p<0.0055$. Again, when comparing the Colombian and Q'eqchi' women for hypothesis H9, no significant difference in body satisfaction was found $(\mathrm{z}=-0.064, p=$ 0.474). A one-way ANOVA for this set of hypotheses for all three nationalities was not significant (in-group 1.56, between-group 0.82, $\mathrm{F}=0.526, p=0.665$ ).

The following hypotheses relate to body-related self-esteem. This was captured on the Body Esteem Scale by Franzoi and Shields (1984) on a five-point Likert scale $(1=\mathrm{I}$ have strong negative feelings to $5=\mathrm{I}$ have strong positive feelings, i.e. 3 is neutral). All results are on average above three, which corresponds to a slightly positive body-related self-esteem. (see Table 3), the value of Q'eqchi' women is highest at 3.96. For hypothesis H10, the comparison of the mean values between German and Q'eqchi' women showed a significant difference $(\mathrm{z}=-4.095, p=$ 0.001). Accordingly, Q'eqchi' women have a significantly higher body-related self-esteem. The effect size according to Cohen (1992) is $d=0.78$ and corresponds to a medium effect. After the Bonferroni correction with a significance limit of $p<$ 0.0083 , the difference remains significant. Likewise, German and Colombian women differ significantly $(\mathrm{z}=-2.352, p=0.010)$ in hypothesis H11. Colombian women had significantly higher body-related self-esteem than German women. The effect size according to Cohen (1992) is $\mathrm{d}=0.40$ and corresponds to a weak effect. However, after the Bonferroni correction with a significance limit of $\mathrm{p}<0.0083$, the difference does not remain significant. There are also statistically significant differences between Colombian and Q'eqchi' women in hypothesis H12 ( $\mathrm{z}=-$ 2.165, $p=0.015$ ). Q'eqchi' showed a higher level of self-esteem. The effect intensity according to Cohen (1992) is $\mathrm{d}=0.71$ and corresponds to a mean effect. 
However, after the Bonferroni correction, the difference does not remain significant. A one-way ANOVA for this set of hypotheses for all three nationalities was significant (in-group 0.38, between-group 3.11, $\mathrm{F}=8.199, p=0.000$ ).

Self-esteem was studied using the Rosenberg Self-Esteem Scale (Rosenberg, 1986). The test consists of ten items and is answered on a five-point Likert scale $(1=$ does not apply at all to $5=$ applies fully). In the sum scores between 10 and a maximum of 50 points can be achieved, the average is 30 . Here, Q'eqchi' women had the weakest and German women had the highest scores. All values are above the mean value between 30 and 40 points (see Table 3). The U-test for hypothesis H13 showed that German women have a significantly higher self-esteem than Q'eqchi'. The effect size according to Cohen (1992) is $d=0.84$ and corresponds to a strong effect. After the Bonferroni correction with a significance limit of $p<$ 0.0083 , the difference remains significant. In hypothesis H14, there was no significant difference between German and Colombian women $(\mathrm{z}=-1.229, p=0.110)$. In contrast, in hypothesis H15, Colombians show a significantly higher self-esteem than Q'eqchi' $(\mathrm{z}=-2.098, p=0.018)$. The effect size according to Cohen (1992) is $\mathrm{d}=0.75$ and corresponds to a medium effect. However, after the Bonferroni correction, the difference does not remain significant. An ANOVA for the negative items of this questionnaire showed no significance (in-group 0.56, between-group $0.04, \mathrm{~F}=0.73, p=0.97$ ) but it was significant for the positive items (in-group 0.82, between-group 15.77, $\mathrm{F}=19.2, p=0.000$ ).

The next hypothesis tested whether there is a positive correlation between body satisfaction and body-related self-esteem, that is, the higher the body-related selfesteem of a person, the higher the body satisfaction. Here, for hypothesis H16, a medium linear correlation ( $\mathrm{rs}=-0.352, p<0.001$ ) was found between body satisfaction and body-related self-esteem. Although a negative rank correlation coefficient appears, it is a positive correlation because high body satisfaction is represented through small scores and high body-related self-esteem is represented by large scores. This means: the higher the body satisfaction, the higher the bodyrelated self-esteem. The effect size is $r=0.35$ and corresponds to a medium effect. After the Bonferroni correction with a significance limit of $p<0.0167$, the relationship remains significant.

The following hypothesis $\mathrm{H} 17$ tested whether there is a positive correlation between body satisfaction and self-esteem, i.e. the happier a person is with her body, the higher her self-esteem. Here, a medium, linear relationship ( $\mathrm{rs}=-0.360, p<$ 0.001 ) could be confirmed. Again, the negative rank correlation coefficient is based on the explanation already given in the last paragraph. The effect size is $r=0.36$ and corresponds to a medium effect. After the Bonferroni correction with a significance limit of $p<0.0167$, the relationship remains significant.

The last hypothesis H18 examined whether there is a positive correlation between body-related self-esteem and self-esteem. Body-related self-esteem and self-esteem were also associated with a linear relationship $(\mathrm{rs}=0.394, \mathrm{p}<$ 0.001). The higher the body-related self-esteem, the higher the self-esteem. The effect size is $r=0.39$ and corresponds to a medium effect. After the Bonferroni correction with a significance limit of $\mathrm{p}<0.0167$, the relationship remains significant. 


\section{Discussion}

The aim of this study is to compare German, Guatemalan Q'eqchi' and Colombian women in terms of their ideal body image, self-perception and body satisfaction. Furthermore, the impact of their body-related self-esteem and self-esteem is examined and compared. The results reveal that German women prefer a significantly slimmer body than Q'eqchi' women, but not significantly slimmer than Colombian women. Colombian women also prefer a slimmer body. These results support the findings of Anderson et al. (1992). Germany is a highly developed country and Colombia is on the upswing (BME, 2014). Both countries have access to a secure food supply. Instead of having children at a young age, many young women attend university and aspire to a career. Q'eqchi' women, on the other hand, do not have a secure food supply. The role of the woman is limited to that of the housewife, spouse, and mother. They do not attend school for long, as at the age of 15 years, the majority of women are already married and have children. Compared to German women, who receive education for an average of 15.8 years, and Colombian women, with a mean of 15.6 years, Q'eqchi' women receive education for an average of only 5.9 years. While $0.7 \%$ of German women do not graduate from school (i.e. a minimum 9 years of school), the proportion of Q'eqchi' women was $61.3 \%$. The percentage of women who reported vocational training or studies for German and Columbia woman was $75.9 \%$ and $69.6 \%$, respectively. For the Q'eqchi' women, this number was only $12.9 \%$, whereas vocational training there may not be equated with what is available in Germany or Colombia. The percentage of Q'eqchi' women who said they did not have paid work was $74.2 \%$, while the percentage of German woman was $1.5 \%$; and in Colombian women $4.3 \%$. It is noticeable that Colombian and German women have comparable average values. Although their country, continents and the cultures are very different from each other, they both live in societies that spread slim body ideals.

The city of Cali is known for its beauty culture. A slender yet curvy body is preferred, and cosmetic surgery is a culturally acceptable way to achieve this. Of the Columbian participants in this study, $62.5 \%$ said they could imagine a modification to their body. Among the German women, this result was $47.4 \%$ and among the Q'eqchi' women $35.5 \%$ — although the only cosmetic modification Q'eqchi' reported a desire for, was dentures (most individuals in Q'eqchi' society lose their teeth at an early age). None of the Q'eqchi' women had previously heard of a modification of the body in terms of cosmetic surgery. It should be noted that it normal for Q'eqchi' to be nearly naked. They do not have showers and they wash themselves in the river with almost everyone else from the village. Women, who give breastmilk to their babies often walk around shirtless, also in public situations. Nudity is not considered the same way as in Western societies. In Q'eqchi' the naked female body is not considered primarily as an erotic or sexual object, but only symbolizes the female gender and fertility.

Another aspect that could influence the preference of a leaner body ideal of German and Colombian study participants is media usage. On a scale between 1 (very often) and 5 (very rare), this was higher in German $(\mathrm{M}=2.82$, i.e. "medium") and Colombian women ( $\mathrm{M}=2.21$, "often") than in Q'eqchi' women $(\mathrm{M}=3.65$, "rare" 
to "very rare"). Again, the value given by the Q'eqchi' women is not representative, as they have a very different relationship to media. In their culture, getting information from the media "often" means visiting the nearest large city about twice a month, as the village does not have access to electricity or electronic media. The ideal of beauty mediated in the media certainly creates a pressure for German and Colombian women, which the Q'eqchi' women do not encounter.

There were no significant differences among the three sample groups regarding their own body perception. However, if the women's BMIs are included, German women rate their body significantly more critically than Q'eqchi' or the Colombians. Colombian women were also more self-critical than the Q'eqchi'. German women demonstrate a clear discrepancy between their self-assessment of their own figure and the desired ideal body image. Their actual body image is overestimated, even though their BMI is low. The data collected from the Columbian women demonstrates similar results. They have a certain average figure according to their BMI, but still desire a slimmer physique. Again, there is a discrepancy between the self-rated figure and the ideal body image. As to Q'eqchi' women, there is no such discrepancy between the self-rated figure and the ideal body image. The actual body image also represents the ideal body image - however, the actual body image is underestimated here.

Interestingly enough, the Q'eqchi' women have the greatest distortion of their own body perception. On average, they estimate their actual physique to be slimmer than they actually are. That could be because in the Guatemalan jungle, there is no such slim body ideal perpetuating throughout their culture. Q'eqchi' women in Nueva Mercedes have neither mirrors nor scales, so they cannot get a picture of their body daily, which could lead to a comparison with others. The traditional clothing consists of a wide, long skirt ("corte") and a wide blouses ("wipil"), which does not emphasize the body and hinders one's ability to perceive differences in the figures of individual women. In contrast, figure-hugging garments are preferred in Germany, and even more so in Colombia.

Q'eqchi' women had a significantly higher body-related self-esteem than German and Colombian women, as demonstrated by the fact that Q'eqchi' are not afraid to show their nakedness. There is the ideal of a slightly fuller woman, and most of the women living there live up to that ideal, which enhances body-related self-esteem. Presumably, the prevailing slim body ideal in German and Colombian society causes the women living there to feel pressured to live up to this ideal. This, in turn, can have a negative effect on body satisfaction (Kreikebaum, 1999) as well as self-esteem (Major et al. 1991; Astleitner and Holzner 2006).

Nevertheless, German and Colombian women have a significantly higher selfesteem than Q'eqchi' women. The fact that Q'eqchi' have the highest body-related self-esteem but also the lowest self-esteem reflects that self-esteem results from various aspects, not just the evaluation of one's own body (Lohaus and Vierhaus 2013, p. 169). For example, German women derive their self-esteem not only from their physical beauty, but from other factors, e.g. a higher social status, better education, or well-paid jobs. In contrast, Q'eqchi' women, even if they are used to it, maintain a very low social position. It is a common occurrence for young women to be sold at the age of about 15 to a husband, whether they wish to marry or not. 
Because of the high number of children that every woman is expected to care for, women are not valued as laborers in Q'eqchi' culture, and they are thrust into the role of motherhood and housewife - a role which often overwhelms them.

Until 7th grade, school in Guatemala is free; after 6th grade, school attendance is only permitted to those who are able to pay for the cost of attendance, and much of the Q'eqchi' are currently taught only through donations and by volunteers. Often, Q'eqchi' women drop out of school after the second grade or do not even attend school at all, which is why there is a very high proportion of illiterate women in their society. In this study, it was observed that women who did not know how to write or read were extremely ashamed of this fact. During the on-site data collection, the questionnaire was often read to them for these reasons, which certainly had an impact on self-esteem. Although Q'eqchi' family fathers work in the fields all day long, the little money is at most sufficient for a family of three. This makes the Q'eqchi' feel their poverty, since they generally have between eight to twelve children.

A key aspect that does not make the results entirely representative is the difference in sample size. Furthermore, the three groups not only have different cultural backgrounds, but also have different educational attainment, employment and quality of life. While the Colombian and German women are from big cities, the Q'eqchi' women live in the jungle of Guatemala where they do not have access to modern technology. Similarly, the participants in the German and Colombian sample groups tend to be considered wealthy, while Q'eqchi' women live in poverty. In addition, the results should not be considered as representative of the corresponding country. There are still many regions in Colombia where people live far from the media and modern social development. Similarly, the results of the Guatemalan sample group do not represent women throughout Guatemala, but can only be traced back to the indigenous tribe of Q'eqchi'.

\section{Publisher's Note}

Springer Nature remains neutral with regard to jurisdictional claims in published maps and institutional affiliations.

Acknowledgements We thank all participants in this study for their willingness to answer our questions. We thank Mrs. B. Smith for correcting the manuscript.

\section{Authors' contributions}

Prof. Dr. Erich Kasten proposed the study, supervised the data collection and evaluation and worked on the creation of the article. Ms. Julia Odinga collected the data in Guatemala, Colombia and Germany and evaluated the data. All authors read and approved the final manuscript. 


\section{Authors' information}

Erich Kasten was born in Germany, he is psychology-professor at the Medical School Hamburg since 2013, before that he worked at the University clinics in Lübeck, Göttingen and Magdeburg and at the Humboldt University in Berlin. He teaches neuroscience, clinical psychology and medical psychology. Research focuses on the neuropsychology of body modification, human beauty and body integrity dysphoria.

Julia Odinga was born in Spain. She studied psychology at the Medical School Hamburg and is now doing her Masters at the Psychological Institute of the University of Hamburg. She works in development aid in South America.

\section{Funding}

There was no funding for this study.

\section{Availability of data and materials}

There are no supporting data.

\section{Ethics approval and consent to participate}

The study received a positive vote from the local ethics committee in Germany. All participants were informed about the purpose of the study and about the voluntary participation. All participants had the right to cancel the survey or have their data deleted.

\section{Consent for publication}

All participants agreed and signed a document (or orally, if they could not write) that their data can be analyzed scientifically and published.

\section{Competing interests}

There are no competing interests.

\section{References}

Action Against Hunger. 2015. Colombia Retrieved from https://www.aktiongegendenhunger.de/laender/lateinamerika/kolumbien.

Anderson, J.L., C.E. Crawford, J. Nadeau, and T. Lindberg. 1992. Was the duchess ofWindsor right? A cross-cultured view of the socio-biology of ideals of female body shape. Ethology and Sociobiology 13: 197-227. https://doi.org/10.1016/0162-3095(92)90033-Z.

Astleitner, H., and B. Holzner. 2006. The influence of gender and body image variables on student self-esteem. Salzburger Beiträge zur Erziehungswissenschaft 10 (1): 37-43.

Berscheid, E., E. Walster, and G. Bohrnstedt. 1973. The happy American body: A survey report. Psychology Today 7: 119-131. 
Blake, C. 2015. How body images in the media affect body satisfaction: A theoretical reconstruction of the causes of action. Wiesbaden: Springer. https://doi.org/10.1007/978-3-658-07750-1.

Blascovich, J., \& Tomaka, J. 1993. „Measures of Self-Esteem“. In J.P. Robinson, P.R. Shaver \& L.S. Wrightsman (Ed.), Measures of Personality and Social Psychological Attitudes (p. 115-160). Ann Arbor: Insititute for social Research.

BMZ: Bundesministerium für wirtschaftliche Zusammenarbeit und Entwicklung 2014. Kolumbien: Situation und Zusammenarbeit. Retrieved from: https://www.bmz.de/de/laender_regionen/lateinamerika/kolumbien/zusammenarbeit/index.html.

Buhrich, N. 1981. Frequency and presentation of anorexia in Malaysia. Australian and New Zealand Journal of Psychiatry 15: 153-155. https://doi.org/10.3109/00048678109159426.

Campbell, J.D. 1990. Self-esteem and clarity of the self-concept. In The self in social psychology, ed. R. Baumeister, 223-239. Hove: Psychology Press. https://doi.org/10.1037/0022-3514.59.3.538.

Cash, T.F. 2012. Cognitive-behavioral perspectives on body image. In Encyclopedia of body image and human appearance, ed. T.F. Cash, 334-342. Cambridge, Massachusetts: Elsevier Academic Press.

Castillo, M.d.P. 2008. The beautiful business of plastic surgery in Cali. In Revista Posiciones, 2. Valle: Universidad del.

Climate-data.org. (n.d.) Climate: Cali Retrieved from https: es.climate-data.org/location/3426/.

Climate-data.org. (n.d.). Climate and weather in Panzós. Retrieved from https://en.climate-data.org/location/46102/.

Cohen, J. 1992. A power primer. Psychological Bulletin 112: 155-159. https://doi.org/10.1037/0033-2909.112.1.155.

Confalonieri, E., E. Gatti, C. Ionio, and D. Traficante. 2008. Body-esteem scale: A validation on Italian adolescents. Testing, Psychometrics, Methodology in Applied Psychology 15 (3): 153-165.

Costantini, M. 2014. Body perception, awareness, and illusions. Wiley Interdisciplinary Review Cohnitive Schience. 5 (5): 551-560. https://doi.org/10.1002/wcs.1309.

Departamento Administrativo Nacial de Planeación (DANE). 2013. Medición del trabajo remunerado en el DANE. Retrieved from: https://www.dane.gov.co/files/noticias/uso_tiempo_freire.pdf.

Depiel. 2016. Cuales son las cirugías más realizadas por las mujeres en Colombia? Retrieved on 6. July 2017 from: http://depiel.com/cuales-son-las-cirugiasplasticas-mas-realizadas-por-las-mujeres-encolombia/ \#.WWPI1hT7Nd0.

Destatis. 2016a. Population - births Retrieved from: https://www.destatis.de/DE/ZahlenFakten/GesellschaftStaat/Bevoelkerung/Geburten/Tabellen/GeburtenMutteralter.html.

Destatis. 2016b. Employment of women: Germany with the second highest quota in the EU Retrieved from https://www.destatis.de/Europa/DE/Thema/BevoelkerungSoziales/Arbeitsmarkt/ArbeitsmarktFrauen.html.

El Ansari, W., and G. Berg-Beckhoff. 2019. Association of Health Status and Health Behaviors with weight satisfaction vs. body image concern: Analysis of 5888 undergraduates in Egypt, Palestine, and Finland. Nutritiens 11 (12). https://doi.org/10.3390/nu11122860.

Ettarh, R., S. Van de Wijver, S. Oti, and Kyobutungi. 2013. Overweight, obesity, and perception of body image among slum residents in Nairobi, Kenya, 2008-2009. Preventing Chronic Disease. 10: E212. https://doi.org/10.5888/pcd10.130198.

Federal Ministry for Economic Cooperation and Development. 2014. Colombia: Situation and cooperation Retrieved from https://www.bmz.de/de/laender_regionen/lateinamerika/kolumbien/zusammenarbeit/index.html.

Federal Ministry for Economic Cooperation and Development. 2017. Latin America and the Carribean: Colombia Retrieved from http://www.bmz.de/de/laender_regionen/lateinamerika/kolumbien/index.html.

Fisseni, H.J. 1997. Lehrbuch der psychologischen Diagnostik. Göttingen: Hogrefe.

Franzoi, S.L., and S.A. Shields. 1984. The body-esteem scale: Multidimensional structure and sex differences in a college population. Journal of Personality Assessment 48: 173-178. https://doi.org/10.1207/ s15327752jpa4802_12.

Frisch, R. E. 1990. Body fat, menarche, fitness, and fertility. In: Anderson, J.L., Crawford, C.B., Nadeau, J., \& Lindberg, T. 1992. Was the duchess of Windsor right? A cross-cultural review of the socioecology of ideals of female body shape. Ethology and Sociobiology, 13(3), 197-227. doi: https://doi.org/10.1093/ oxfordjournals.humrep.a.136582.

Gao, X., X. Wang, and B. Zhu. 2017. The distribution of Chinese minority populations and its change based on the study of the Hu Huanyong line. International Journal of Anthropology Ethnology 1: 2. https:// doi.org/10.1186/s41257-017-0004-9.

Grabe, S., L.M. Ward, and J.S. Hydem. 2008. The role of the media in body image concerns among women: A meta-analysis of experimental and correlational studies. Psychological Bulletin 134 (3): 460-476. https://doi.org/10.1037/0033-2909.134.3.460. 
ISAPS: International Society of Aesthetic Plastic Surgery. 2018. International study on Aesthetic \& Cosmetic Procedures Performed in 2018 Retrieved from https://www.isaps.org/wp-content/uploads/2019/12/ ISAPS-Global-Survey-Results-2018-new.pdf.

Javier, S.J., and F.Z. Belgrave. 2019. "I'm not White, I have to be pretty and skinny": A qualitative exploration of body image and eating disorders among Asian American women. Asian American Journal of Psychology 10 (2): 141-153. https://doi.org/10.1037/aap0000133.

Käufer, T. 2013. Cult around the butt in the city of the tight buttocks Retrieved from https://www.welt.de/vermischtes/article121259406/Kult-um-den-Po-in-der-Stadt-der-strammen-Hintern.html.

Klitzke Rozas, B. 2015. UN report: 70 percent poverty in Guatemala Retrieved from https://amerika21.de/2 015/12/138840/menschliche- entwicklung-2015.

Kreikebaum, S. P. 1999. Körperbild, Körperzufriedenheit, Diätverhalten und Selbstwert bei Mädchen und Jungen im Alter von Sieben bis dreizehn Jahren : Eine interkulturelle Vergleichsstudie (USA - D) und Längsschnittuntersuchung (D) (Body image, body satisfaction, dieting and self-esteem from girls and boys between the ages of seven and thirteen: A comparative study (USA - D) and longitudinal examination (D)). Köln: Universität zu Köln, Institut für Psychologie.

Kruchem, T. 2015. Am Tropf von Big Food: Wie die Lebensmittelkonzerne den Süden erobern und arme Menschen krank machen. Bielefeld: Transcript Verlag.

Kruchem, T. 2016. The silent hunger of Guatemala Retrieved from https://www.deutschlandfunk.de/aflatoxine-der-stille-hunger-von-guatemala.676.de.html?dram:article_id=353979.

Lerner, R., J. Lerner, J. Hess, and J. Schwab. 1991. Physical attractiveness and psychological functioning among early adolescents. Journal of Early Adolescence 11: 300-320.

Liu, H., and Y. Zhang. 2018. Building a community of shared future for humankind -- an ethnological perspective. International Journal of Anthropology Ethnology 2: 7. https://doi.org/10.1186/s41257-018-0015-1.

Lohaus, A., and M. Vierhaus. 2013. Developmental psychology (2nd Ed.). Heidelberg: Springer.

Major, B., M. Testa, and W.H. Bylsma. 1991. Response to upward and downward social comparisons. The impact of esteem-relevance and perceived control. In Social comparison. Contemporary theory and research, ed. J. Suls and T.A. Willst, 237-260. Hillsdale: Erlbaum. https://doi.org/10.1348/ $014466605 \times 53479$.

Mendelson, B.K., M.J. Mendelson, and D.R. White. 2001. Body-esteem scale for adolescents and adults. Journal of Personality Assessment 76 (1): 90-106. https://doi.org/10.1207/S15327752JPA7601_6.

Monteiro, C.A., E.C. Moura, W.L. Conde, and B.M. Popkin. 2004. Socioeconomic status and obesity in adult populations of developing countries: A review. Bulletin of the World Health Organization 82: 940-946.

Polivy, J., and P.C. Herman. 2002. Causes of eating disorders. Annual Review of Psychology 53: 187-213. https://doi.org/10.1146/annurev.psych.53.100901.135103.

Profamilia. 2009. Youth pregnancies in Germany Retrieved from https:// www.profamilia.defileadmin/publikationen/Fachpublikationen/fakten_Hintergruende_Jugendschwangerschaften1.pdf.

Puhl, R. \& Brownell, K.D. 2012. Bias, Discrimination, and Obesity. Obesity Research, 9 (12):788-805. https://doi.org/10.1038/oby.2001.108.

Pullmann, H., and J. Allik. 2000. The Rosenberg self-esteem scale: Its dimensionality, stability and personality correlates in Estonian. Personality and Individual Differences 28: 701-715. https://doi.org/10.1016/ S0191-8869(99)00132-4.

Quetelet, A. 1832. Recherches Sur le poids de l'homme aux different âges (research on the weight of man at different ages). In Nouveaux memoires de l'Academie Royale des sciences et belle-Lettres de Bruxelles, 7.

Röhricht, F., K.P. Seidlicher, P. Joraschky, A. Borkenhagen, H. Lausberg, E. Lemche, T. Loew, U. Porsch, K. Schreiber Willnow, and K. Tritt. 2004. Consensus paper on terminological delimitation of partial aspects of body experience in research and practise. Psychotheraphy Psychiatry Medicine 54: 1-8. https:// doi.org/10.1055/s-2004-834551.

Rosenberg, M. 1986. Conceiving the self. Malabar (Florida): Krieger Publishing Company.

Salter, M. 1999. Body image and body image disorder. Wiesbaden: Ullstein MedicalVerlagsgesellschaft.

Schemer, C. 2003. Slim and sick through media beauties? On the effect of attractive female media actors on the body image of women. Medien \& Kommunikationswissenschaft 51 (3): 523-540. https://doi.org/10. 5167/uzh-26741.

Slade, P.D. 1994. What is body image? Behavior Research and Therapy 32: 487-502. https://doi.org/10. 1016/0005-7967(94)90136-8.

Stern, J.M. 2018. Transcultural aspects of eating disorders and body image disturbance. Nordic Journal of Psychiatry 72 (1): S23-S26. https://doi.org/10.1080/08039488.2018.1525642. 
Stunkard, A.J., T. Sorensen, and F. Schulsinger. 1983. Use of the Danish adoption register for the study of obesity and thinness. IRes. Publ. Assoc. Res. Nerv. Ment. Dis. 60: 115-120.

Suárez Calle, H.A. 2015. Management report and splicing of the municipal public health secretary of Santiago de Cali Retrieved from http://calisaludable.cali.gov.co/planeaciol2015_PublicacionesProceso_ Empalme_2015/INFORME\%20DE\%20EMPALME\%20SSPM\%202015.pdf.

Terhoeven, V., C. Nikendei, T. Bärninghausen, M. Bountogo, H.C. Friedrich, L. Ouermin, A. Sié, and G. Harling. 2019. Eating disorders, body image and media exposure among adolescent girls in rural Burkina Faso. Tropical Medicine \& International Health. https://doi.org/10.1111/tmi.13340.

Thompson, J.K., L.J. Heinberg, M. Altabe, and S. Tantleff-Dunn. 1999. Exacting beauty. Theory, assessment, and treatment of body image disturbance. Washington: American Psychological Association. https://doi. org/10.1037/10312-000.

Thornton, B., and R.M. Ryckman. 1991. Relationship between physical attractiveness, physical effectiveness, and self-esteem: A cross-sectional analysis among adolescents. Journal of Adolescence 14: 58-98. https://doi.org/10.1016/0140-1971(91)90047-U.

Tucker, L.A. 1981. Internal structure, fact or satisfaction and reliability of body cathexis scale. Perceptual and Motor Skills 53: 891-896. https://doi.org/10.2466/pms.1981.53.3.891.

Twigg, M. 2017. Where plastic is fantastic. In The World's cosmetic surgery capitals Retrieved from https:// www.businessoffashion.com/articles/global-currents/where-plastic-is-fantastic-the-worlds-cosmetic-surgery-capitals.

UNESCO. 2006. World report: Education for all Retrieved from http://unesdoc.unesco.org/images/0014/ 001442/144270ger.pdf.

UNICEF. 2010. Guatemala: Malnutrition Retrieved from https://www.unicef.org/guatemala/english/overview_18012.htm.

Wagner, T. 2013. Versteckter Hunger - Einseitige Ernährung gefährdet die Gesundheit. Retrieved from: http://www.deutschlandfunk.de/versteckter-hunger.697.de.html?dram:article_id=239275.

Walter, J.D. 2015. Less poverty in Colombia Retrieved from http://www.dw.com/de/weniger-armut-in-kolumbien/a-18346508.

World Health Organization. 2016. Obesity and overweight Retrieved from http://www.who.int/mediacentre/ factsheets/fs311/en/.

Yu, K., and M. Perez. 2019. The association between maternal criticism and body dissatisfaction on disordered eating pathology across racial and ethnic groups. Cultural Diversity \& Ethnic Minority Psychology. https://doi.org/10.1037/cdp0000277.

Zhang, J. 2019a. Educational diversity and ethnic cultural heritage in the process of globalization. International Journal of Anthropology Ethnology 3: 7. https://doi.org/10.1186/s41257-019-0022-x.

Zhang, J. 2019b. New functionalism: Rejuvenating historical and cultural heritage through urban revival. International Journal of Anthropology Ethnology 3: 8. https://doi.org/10.1186/s41257-019-0023-9.

Zhou, D., X. Zhan, Y. Cao, and L. Chen. 2019. An overview of anthropological regional studies. International Journal of Anthropology Ethnology 3: 6. https://doi.org/10.1186/s41257-019-0018-6. 